\title{
Metabolic syndrome and population attributable risk among HIV/AIDS patients: comparison between NCEP-ATPIII, IDF and AHA/NHLBI definitions
}

Paulo R Alencastro ${ }^{1,2}$, Fernando H Wolff2, ${ }^{2,3}$, Renato R Oliveira', Maria Letícia R Ikeda ${ }^{1,4}$, Nêmora T Barcellos ${ }^{1,3}$, Ajácio B M Brandão ${ }^{2}$ and Sandra C Fuchs $s^{3,4,5^{*}}$

\begin{abstract}
Background: Metabolic Syndrome (MetS) is based on the same individual components, but has received several amendments to the original definition. In this study, we verified the prevalence of metabolic syndrome according to different criteria, and the impact of each component on the diagnostic.

Methods: This cross-sectional study enrolled HIV infected patients from a HIV/AIDS reference Center in southern Brazil. Metabolic syndrome was identified according to the National Cholesterol Education Program Expert Panel on Detection, Evaluation, and Treatment of High Blood Cholesterol in Adults (NCEP-ATPIII), the International Diabetes Federation (IDF) and the American Heart Association/National Heart, Lung and Blood Institute (AHA/NHLBI) criteria, and using a standardized questionnaire and blood testing.

Results: A sample of 1240, out of 1295, HIV-infected patients was enrolled. Males were on average older, more educated, and had shorter time since the HIV diagnosis. The population attributable risk (PAR) for waist circumference explained $80 \%$ of the prevalence among men and women (AHA/NHLBI criteria). Triglycerides had the highest impact on prevalence of metabolic syndrome according to all criteria, independently of age, skin color and HAART use, among men.
\end{abstract}

Conclusions: In this large sample of HIV infected patients, the overall prevalence of metabolic syndrome, under either classification, was noticeable and the AHA/NHLBI definition accounted for the highest prevalence.

Keywords: Metabolic syndrome, Population attributable risk, HIV/AIDS, NCEP-ATPIII, IDF, AHA/NHLBI, Waist circumference

\section{Background}

Metabolic syndrome (MetS) comprises a set of aggregated risk factors including hypertension, central obesity, abnormal fasting glucose, and dyslipidemia which increase the risk of cardiovascular disease [1-4] and type 2 diabetes mellitus [1-4]. Since the third report of the

\footnotetext{
* Correspondence: scfuchs@terra.com.br

${ }^{3}$ Postgraduate Studies Program in Epidemiology, School of Medicine, Universidade Federal do Rio Grande do Sul, R. Ramiro Barcelos 2600, Porto Alegre, RS CEP 90035-003, Brazil

${ }^{4}$ Postgraduate Studies Program in Cardiology, School of Medicine, Universidade Federal do Rio Grande do Sul, R. Ramiro Barcelos 2600, Porto Alegre, RS CEP 90035-003, Brazil

Full list of author information is available at the end of the article
}

National Cholesterol Education Program Expert Panel on Detection, Evaluation, and Treatment of High Blood Cholesterol in Adults (NCEP-ATPIII) several amendments have been incorporated in a working definition of MetS [5,6]. The International Diabetes Federation (IDF) criteria are based on the same components, but adopted racial/ethnic cutoffs for waist circumference. It have included waist circumference (WC) as a prerequisite for MetS and the treatment for previous conditions as additional criteria of abnormality $[4,7]$.

The revision of NCEP-ATPIII guideline in $2005[6,8,9]$ incorporated the treatment for previous disorders (hypertension, diabetes, dyslipidemia) and reduced the cutoff for

\section{Biomed Central}


serum glucose $(100 \mathrm{mg} / \mathrm{dL})$ as criteria for abnormality. Recently, a consensus between representatives of the American Heart Association/National Heart, Lung and Blood Institute (AHA/NHLBI) and IDF presented the AHA/NHLBI definition of metabolic syndrome [10]. Central obesity was removed as a prerequisite, so any three risk factors, out of five, make the diagnosis of MetS.

Changes in the thresholds of MetS components account for differences in prevalence rates of this diagnosis, changing also the population attributable risk (PAR) of their components. Prevalence of MetS have been investigated for non-HIV-infected subjects [11,12], but are scarcely reported for the HIV-infected population [13] or compared to the general population [14]. In addition, some components of MetS are particularly vulnerable to the effect of highly active antiretroviral therapy (HAART) $[15,16]$, and it might be time-dependent. This study verified the prevalence of metabolic syndrome according to the NCEP-ATPIII, IDF and the AHA/NHLBI criteria, and investigated the PAR of each component on prevalence rates among $\mathrm{HIV}$-infected adults.

\section{Material and methods}

This cross-sectional study enrolled HIV infected patients, aged 18 to 79 years, from a public health Center for AIDS Care and Treatment in Porto Alegre, southern Brazil. This hospital is one of three reference centers, which provide HIV treatment for patients living in the metropolitan area, other cities of the state or even from other states. A systematic consecutive sample of outpatients, attending to the center at the time of data collection, with confirmed HIV infection, was eligible. Those with mental retardation, restriction of freedom or pregnant women were excluded. The study was approved by the institutional review board of the Hospital de Clínicas de Porto Alegre- Comissão de Ética em Pesquisa, GPPG: 06-243, which is accredited by the Office of Human Research Protections. All participants signed a consent form.

\section{Studied variables}

Metabolic syndrome according to the NCEP-ATPIII [9] was identified for patients who had at least three out of five components: increased waist circumference (WC; men $\geq 102 \mathrm{~cm}$ and women $\geq 88 \mathrm{~cm}$ ), triglycerides $\geq 150$ $\mathrm{mg} / \mathrm{dL}$ or specific treatment, low high-density lipoprotein cholesterol (HDL-C) (men $<40 \mathrm{mg} / \mathrm{dL}$, women $<50 \mathrm{mg} / \mathrm{dL}$ or specific treatment), blood pressure $\geq 130 / \geq 85 \mathrm{mmHg}$ or anti-hypertensive treatment, and fasting glucose $>100 \mathrm{mg} / \mathrm{dL}$, or previous diagnosis of type 2 diabetes mellitus or antidiabetic treatment. The IDF criteria for MetS [4,7] were based on abnormal WC, in addition to two or more components as those used by the revised NCEP-ATP III [9]. The WC cutoffs vary by racial/ethnic group, but since there are no specific cutoffs for Brazilians, we used those recommended by the IDF for South Asians $(\geq 90 \mathrm{~cm}$, for men, and $\geq 80 \mathrm{~cm}$, for women). The AHA/NHLBI definition [10] used the same criteria of the revised NCEP-ATP III [9], but the country specific WC cutoff suggested by the IDF $[4,7]$. For this study, we used those for South Asians.

Potential confounding factors were also studied: gender, age, skin color (self-assessed), years at school, time since the diagnosis of HIV (reported by the patient and confirmed in medical records), and the use of HAART in the 12 months previous to the interview (recorded in medical record).

\section{Data collection}

Patients were interviewed at their routine medical visits by research assistants trained and certified to participate in the study. A standardized questionnaire was used to collect the data, which included questions pertaining to demographic, socioeconomic, and other characteristics, and quality control for data gathering was carried out for a $10 \%$ systematic random sample of the interviews. Variables related with HIV infection, use of HAART were obtained at the interview and confirmed with medical records.

Standardized assessments of blood pressure $[17,18]$ were conducted using a validated automatic device (OMRON CP-705) [19], and the average of eight measurements in two office visits was used to diagnose hypertension. Waist circumference was measured with a flexible inelastic tape placed on the midpoint between the lower rib margin and the iliac crest in a perpendicular plane to the long axis of the body, while the subject stood balanced on both feet, approximately $20 \mathrm{~cm}$ apart, and with both arms hanging freely $[4,20]$.

A 12 hours fasting glucose and lipid profile were requested for patients who had not been tested in the last three months. Laboratory tests were performed using standardized techniques [21-24].

\section{Sample size and statistical analysis}

The sample size calculation was based on estimated MetS prevalence rates among patients exposed to HAART (25\%) and non-exposed (15\%) [14], with $80 \%$ of power and 0.05 significance level (two-tailed). A sample size of 510 patients would be necessary whether a ratio of $1: 1$ of non-exposed to exposed to HAART were enrolled, increasing to 741 patients for a ratio of 1:3.

Bivariate analyses were conducted stratified by gender, and statistical significance was assessed by Pearson chisquare test or analysis of variance, using the Statistical Package for the Social Sciences (SPSS Inc., version 16.0 Chicago, Il, USA). The Interactive Risk Attributable Program (IRAP, version 2.2.0, National Cancer Institute, Bethesda, MD, USA) software [25,26] was used to calculate the PAR and corresponding 95\% confidence intervals 
(95\%CI) for MetS components after adjustment for other exposures and potential confounders. The PAR allows estimating the proportion of disease burden causally explained by the components of the MetS [27].

\section{Results}

A sample of 1240, out of 1295, HIV-infected patients was enrolled, 15 refused to participate and 40 fulfilled the exclusion criteria. Table 1 shows that participants were aged $38.6 \pm 10.1$ years and mostly were whites. Males were on average older, completed more years at school, and the length of time since the HIV diagnosis was longer than for women. The use of protease inhibitors, on the other side, was more frequent among women.

Table 2 shows that the waist circumference (IDF definition), triglycerides, and HDL-C levels were the most prevalent components. All components levels, but fasting glucose, were significantly different among men and women. Abnormal triglycerides were more prevalent among men, and waist circumference (IDF definition) among women. However, there were no statistically significant differences on MetS prevalence based on the three criteria.

Figure 1 shows that metabolic syndrome by AHA/ NHLBI definition increased with age $(P$ value $<0.001)$ for men and women $(\mathrm{P}$ value $=0.001)$ on HAART use. However, among treatment naïve participants it increased with age $(\mathrm{P}<0.001)$, but it did not vary markedly by sex $(\mathrm{P}$ value $=0.1)$.

Table 3 shows the adjusted PAR for components of the MetS by sex. The PAR for waist circumference explained $80 \%$ of the prevalence of AHA/NHLBI definition among men, while triglycerides accounted for the highest impact on prevalence of metabolic syndrome according to all criteria, independently of age, skin color and HAART use.
For women, waist circumference explained at least $80 \%$ of prevalence of MetS according the NCEP-ATPIII or AHA/NHLBI criteria, while for the IDF definition similar impacts were detected for HDL-C, triglycerides, and blood pressure components.

\section{Discussion}

In this large sample of HIV infected patients, the overall prevalence of metabolic syndrome, under either classification, was noticeable. The AHA/NHLBI definition accounted for higher prevalence of MetS than those observed in the NCEP-ATPIII and IDF, which is in accordance with lower cutoff and lacking of the obligatory abnormal waist circumference. The overall prevalence of most MetS components differed considerably among men and women, but the overall prevalence did not vary by sex. Even though the three definitions of MetS were based on the same components, the cutoffs for waist circumference differ markedly on NCEP-ATPIII and IDF, as well as the hierarchy of the central obesity.

This study also estimated the PAR in order to assess separately the contribution of each component on MetS prevalence. This approach assumes that the abnormal MetS components are randomly distributed among the HIV-infected population, but they might be clustered as a consequence of HAART, and, therefore, the PAR could be overestimated. HAART can cause abnormality on lipids and glucose metabolisms $[15,16]$, but these changes could also be caused by the HIV infection $[28,29]$. In order to minimize the confounding factors, PAR were adjusted for age, skin color, and HAART use.

This study detected lower prevalence rate of MetS, by NCEP-ATPIII definition, than previously described [30-32], which could be attributed to the similar number of men and women, and to the $66 \%$ of subjects on HAART, versus the dominance of men and HAART use in those studies. The estimate of MetS based on the IDF

Table 1 Characteristics of the HIV/AIDS patients [N (\%) or mean \pm SD]

\begin{tabular}{|c|c|c|c|c|}
\hline & Overall & $\begin{array}{c}\text { Men } \\
(\mathrm{N}=1240)\end{array}$ & $\begin{array}{l}\text { Women } \\
(\mathrm{N}=628)\end{array}$ & $\begin{array}{l}P \text { value } \\
(\mathrm{N}=612)\end{array}$ \\
\hline Age (years) & $38.6 \pm 10.1$ & $39.5 \pm 9.6$ & $37.7 \pm 10.4$ & 0.003 \\
\hline Years at school & $7.5 \pm 4.1$ & $8.1 \pm 4.2$ & $6.8 \pm 3.8$ & $<0.001$ \\
\hline White skin color & $692(55.8)$ & $380(60.5)$ & $312(51.0)$ & $<0.001$ \\
\hline Viral load $<50$ copies $/ \mathrm{ml}$ & $508(41.6)$ & $268(43.4)$ & $240(39.8)$ & 0.2 \\
\hline CD4 (cels $\left./ \mathrm{mm}^{3}\right)$ & & & & 0.3 \\
\hline$<200$ & $181(14.8)$ & $99(16.0)$ & $82(13.5)$ & \\
\hline $200-350$ & $295(24.0)$ & $153(24.7)$ & $142(23.4)$ & \\
\hline$>350$ & $751(61.2)$ & $368(59.4)$ & $383(63.1)$ & \\
\hline HAART use & $815(65.7)$ & $420(66.9)$ & $395(64.5)$ & 0.4 \\
\hline Protease inhibitor use & $468(37.7)$ & $212(33.8)$ & $257(42.0)$ & 0.003 \\
\hline Time since HIV diagnosis (years) & $4.9 \pm 4.2$ & $5.2 \pm 4.6$ & $4.6 \pm 3.8$ & 0.01 \\
\hline
\end{tabular}


Table 2 Prevalence of metabolic syndrome and its components according to criteria, by sex $[\%$ and $(95 \% \mathrm{CI})]$

\begin{tabular}{|c|c|c|c|c|}
\hline & Overall & $\begin{array}{c}\text { Men } \\
(\mathrm{N}=1240)\end{array}$ & $\begin{array}{l}\text { Women } \\
(\mathrm{N}=628)\end{array}$ & $\begin{array}{l}P \text { value } \\
(\mathrm{N}=612)\end{array}$ \\
\hline Abnormal waist circumference ${ }^{f}$ & $20.9(18.6-23.2)$ & $8.1(6.0-10.2)$ & $34.0(30.2-37.8)$ & $<0.001$ \\
\hline 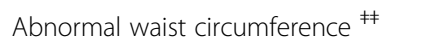 & $46.4(43.6-49.2)$ & $34.7(31.0-38.4)$ & $58.3(54.4-62.2)$ & $<0.001$ \\
\hline Blood pressure $\geq 130 / 85 \mathrm{mmHg}^{*}$ & $28.3(25.8-30.8)$ & $31.7(28.1-35.3)$ & $24.8(21.4-28.2)$ & 0.007 \\
\hline HDL-Cholesterol $<40$ or $<50 \mathrm{mg} / \mathrm{dl}^{*}$ & $38.8(36.1-41.5)$ & $33.8(30.1-37.5)$ & $44.0(40.1-47.9)$ & $<0.001$ \\
\hline Triglycerides $\geq 150 \mathrm{mg} / \mathrm{dl}^{*}$ & $35.9(33.2-38.6)$ & $41.8(37.9-45.7)$ & $29.9(26.3-33.5)$ & $<0.001$ \\
\hline Fasting glucose $\geq 100 \mathrm{mg} / \mathrm{d}^{*}$ & $15.1(13.1-17.1)$ & $15.1(12.3-17.9)$ & $15.0(12.2-17.8)$ & 0.9 \\
\hline \multicolumn{5}{|l|}{ Prevalence of metabolic syndrome } \\
\hline NCEP-ATPIII & $17.2(12.1-22.3)$ & $15.2(7.9-22.5)$ & $19.2(12.1-26.3)$ & 0.06 \\
\hline IDF & $22.1(17.2-27.0)$ & $20.7(13.7-27.7)$ & $23.5(16,5-30.5)$ & 0.2 \\
\hline AHA/NHLBI & $24.7(19.8-29.5)$ & $24.6(17.7-31.4)$ & $24.8(17.9-31.7)$ & 0.9 \\
\hline
\end{tabular}

* Abnormal values or on pharmacological treatment.

${ }^{\ddagger}$ Cutoffs by sex: NCEP-ATPIII $\geq 102 \mathrm{~cm}$ in men, $\geq 88 \mathrm{~cm}$ in women.

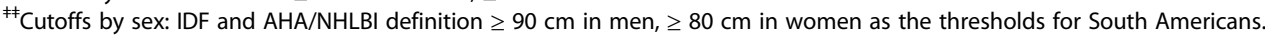

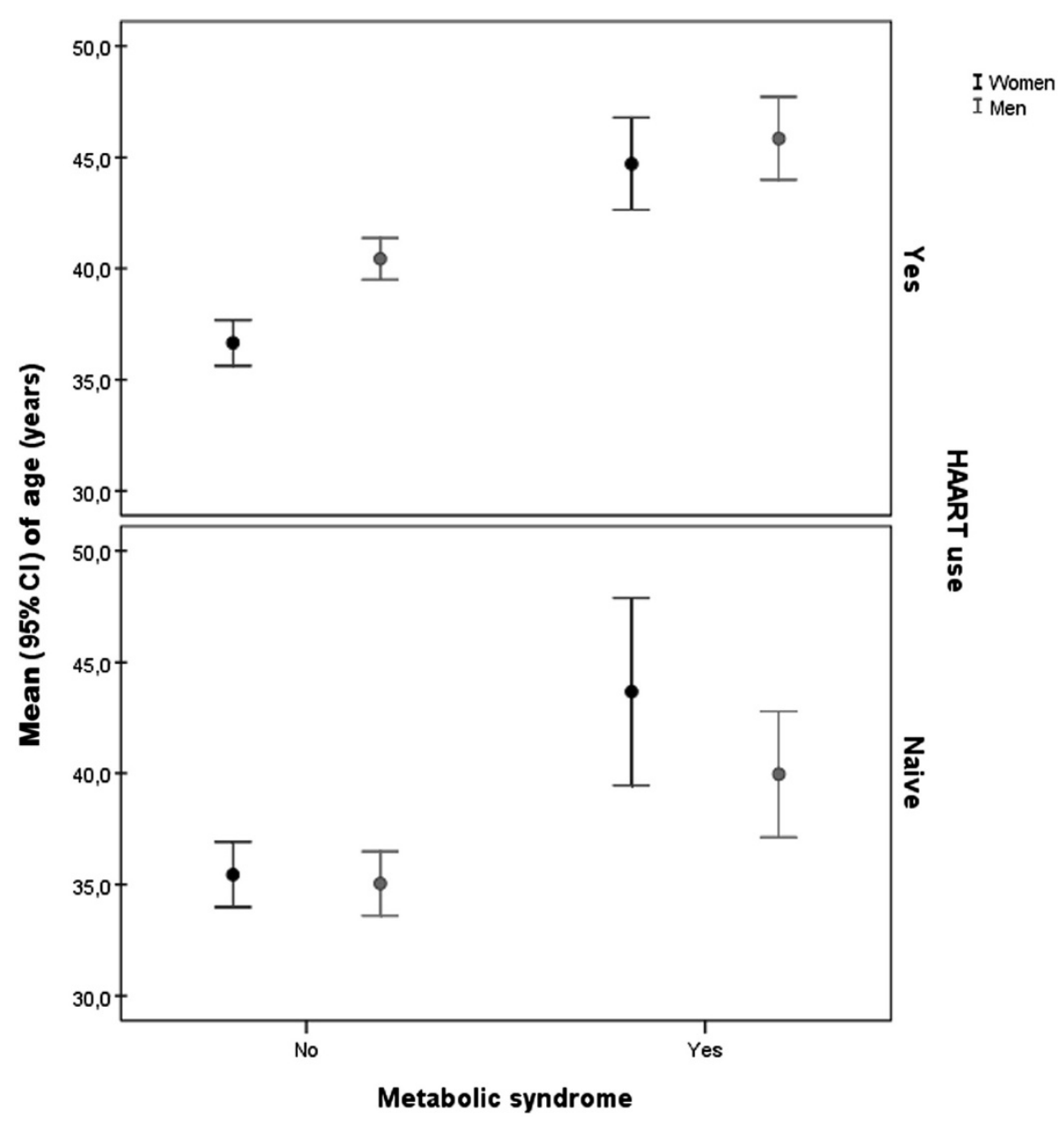

Figure 1 Age distribution of subjects with Metabolic Syndrome according to the AHA/NHLBI $(P$ value $<0.001)$ by sex $(P$ value $=0.001)$ among HAART users and naïve participants ( $P$ values $<0.001$ and 0.1 , respectively). 
Table 3 PAR $^{\dagger}(95 \% \mathrm{CI})$ for metabolic syndrome components according to the criteria, by sex

\begin{tabular}{|c|c|c|c|}
\hline & NCEP-ATPIII & IDF & AHA/NHLBI \\
\hline \multicolumn{4}{|l|}{ Men } \\
\hline Abnormal waist circumference * & $33.1(23.1-43.1)$ & 100.0 & $80.6(73.3-87.8)$ \\
\hline $\mathrm{HDL}$-Cholesterol $<40$ or $<50 \mathrm{mg} / \mathrm{dl}^{\ddagger}$ & $65.2(52.9-77.5)$ & $37.9(25.2-50.6)$ & $50.2(39.6-60.7)$ \\
\hline Triglycerides $\geq 150 \mathrm{mg} / \mathrm{dl}$ & $88.8(80.9-96.7)$ & $74.3(64.7-83.9)$ & $79.4(71.7-87.2)$ \\
\hline Fasting glucose $\geq 100 \mathrm{mg} / \mathrm{d}$ & $42.6(31.2-53.9)$ & $33.5(23.9-43.2)$ & $37.1(28.5-45.7)$ \\
\hline Blood pressure $\geq 130 / 85 \mathrm{mmHg}$ & $68.0(56.5-79.6)$ & $55.4(44.2-66.7)$ & $59.2(49.5-68.9)$ \\
\hline \multicolumn{4}{|l|}{ Women } \\
\hline Abnormal waist circumference ${ }^{*}$ & $80.4(72.1-88.7)$ & 100.0 & $89.8(82.9-96.7)$ \\
\hline $\mathrm{HDL}$-Cholesterol $<40$ or $<50 \mathrm{mg} / \mathrm{dl}^{\ddagger}$ & $66.7(55.8-77.6)$ & $60.7(50.1-71.2)$ & $63.0(53.1-72.9)$ \\
\hline Triglycerides $\geq 150 \mathrm{mg} / \mathrm{dl}$ & $64.1(53.5-74.7)$ & $61.2(51.7-70.8)$ & $62.2(53.0-71.4)$ \\
\hline Fasting glucose $\geq 100 \mathrm{mg} / \mathrm{d}$ & $44.5(34.5-54.4)$ & $38.9(30.0-47.9)$ & $40.8(32.3-49.4)$ \\
\hline Blood pressure $\geq 130 / 85 \mathrm{mmHg}$ & $62.6(52.5-72.8)$ & $57.4(47.9-66.9)$ & $58.8(49.7-67.8)$ \\
\hline
\end{tabular}

${ }^{\dagger}$ PAR: Population Attributable Risk adjusted for age, skin color, and HAART use.

* NCEP-ATPIII (National Cholesterol Education Program-Adult Treatment Panel III) $\geq 102 \mathrm{~cm}$ in men, $\geq 88 \mathrm{~cm}$ in women; IDF (International Diabetes Federation) and AHA/NHLBI (American Heart Association/National Heart, Lung and Blood Institute) definition $\geq 90 \mathrm{~cm}$ in men, $\geq 80 \mathrm{~cm}$ in women according the thresholds for South Americans.

definition verified in this study was similar [14] or higher [13] than other studies, which can be partially explained by the high lipodystrophy rate detected among Italian volunteers [33], and the waist circumference cutoffs, which for Brazilians should be the same as those recommended for the South Asians [4,7].

This study detected high prevalence of MetS for men and women with abnormal waist circumference by the IDF and AHA/NHLBI definition. The cutoffs for waist circumference used for South Asians might be excessively low for Brazilians, but they have been previously used in different contexts among non HIV-infected populations $[34,35]$. The trend for higher prevalence of metabolic syndrome among women might be related to their increased prevalence of central obesity, abnormal HDL-cholesterol, and use of protease inhibitors in comparison with men. Since waist circumference is a mandatory component of the IDF, its impact on MetS prevalence was conceivably $100 \%$.

This study detected lower MetS prevalence by IDF than observed in the general population of Greece [36,37]. Probably, those differences could be attributed to the cutoffs for waist circumference that used ethnic recommendations for abdominal obesity and to lower mean age of HIV-infected patients, which is directly related to abdominal obesity $[38,39]$.

The highest impact of triglycerides and waist circumference suggest that there are consequences associated with the MetS definition adopted to implement any preventive strategy. However, the other components also contributed to the metabolic syndrome burden, and changing their status could result on a substantial reduction on MetS due to triglycerides in males, or waist circumference, in women. The PAR of MetS components might be used to assess the impact of comorbidities, the need for comorbidities treatment, and the HAART toxicity of specific drugs [40]. Interventions to face the burden of metabolic syndrome as well as to determine the health care priority among those who needs medical attention and are at risk for cardiovascular disease are also potential uses for PAR in this area of knowledge.

\section{Conclusions}

In conclusion, the increasing number of antiretroviral agents, longer duration of HAART use, and ageing of the HIV population, might contribute to the growing prevalence of metabolic syndrome and to reduce the life expectancy of HIV-infected patients. This approach of measuring the impact of MetS components on PAR might be useful for comparing the effect of interventions targeting reduction of metabolic syndrome prevalence among HIV-infected populations.

\section{Abbreviations}

MetS: Metabolic syndrome; PAR: Population attributable risk; NCEPATPIII: National Cholesterol Education Program Expert Panel on Detection, Evaluation, and Treatment of High Blood Cholesterol in Adults; IDF: International Diabetes Federation; AHA/NHLBI: American Heart Association/National Heart, Lung and Blood Institute; WC: Waist circumference.

\section{Competing interests}

The authors declare that they have no conflict of interest.

\section{Authors' contributions}

All authors design the study. PA, RO, and MLI collected and analyzed the data. PA, FHW, AB, and NB wrote the manuscript. SF analyzed the data, made substantial contribution to the discussion, and reviewed the final version of the manuscript. All authors read and approved the final manuscript. 


\section{Acknowledgment}

This study was funded, in part, by the Ministry of Health/Secretariat of Health Surveillance/National STD and AIDS Programme (MOH/SHS/NAP), National Counsel of Technological and Scientific Development (CNPq), the National Institute for Science and Technology for Health Technology Assessment (IATS/Brazil)-CNPq/Brazil, FIPE-Hospital de Clínicas de Porto Alegre, RS, Brazil. The authors thank the personnel staff, physicians and patients of the Hospital Sanatório Partenon, Therapeutic Assistance Service, for their collaboration to make this study possible.

\section{Author details}

${ }^{1}$ Hospital Sanatório Partenon, Health Secretariat of State of Rio Grande do Sul, Av. Bento Goncalves, 3722, Porto Alegre, RS CEP: 90650-001, Brazil. ${ }^{2}$ National Institute for Science and Technology for Health Technology Assessment (IATS/CNPq), Hospital de Clínicas de Porto Alegre. R. Ramiro Barcelos 2350, Centro de Pesquisas, Cardiolab-Hipertensão, Porto Alegre, RS CEP 90035-003, Brazil. ${ }^{3}$ Postgraduate Studies Program in Epidemiology, School of Medicine, Universidade Federal do Rio Grande do Sul, R. Ramiro Barcelos 2600, Porto Alegre, RS CEP 90035-003, Brazil. ${ }^{4}$ Postgraduate Studies Program in Cardiology, School of Medicine, Universidade Federal do Rio Grande do Sul, R. Ramiro Barcelos 2600, Porto Alegre, RS CEP 90035-003, Brazil. ${ }^{5}$ Centro de Pesquisa Clínica Hospital de Clínicas de Porto Alegre, Universidade Federal do Rio Grande do Sul, Ramiro Barcellos, 2350, $5^{\circ}$ andar 90.035-000, Porto Alegre, RS, Brazil.

Received: 12 August 2012 Accepted: 2 October 2012 Published: 4 October 2012

\section{References}

1. Ford ES: Risks for all-cause mortality, cardiovascular disease, and diabetes associated with the metabolic syndrome: a summary of the evidence. Diabetes Care 2005, 28:1769-1778

2. Lorenzo C, Williams K, Hunt KJ, Haffner SM: The National Cholesterol Education Program - Adult Treatment Panel III, International Diabetes Federation, and World Health Organization definitions of the metabolic syndrome as predictors of incident cardiovascular disease and diabetes. Diabetes Care 2007, 30:8-13.

3. Hall WD, Watkins LO, Wright JT Jr, Wenger NK, Kumanyika SK, Gavin JR 3rd, Ferdinand KC, Watson K, Clark LT, Flack JM, Reed JW, Horton EW, Saunders E, African-American Lipid and Cardiovascular Council: The metabolic syndrome: recognition and management. Dis Manag 2006, 9:16-33.

4. Alberti KG, Zimmet P, Shaw J: The metabolic syndrome-a new worldwide definition. Lancet 2005, 366:1059-1062.

5. Adult Treatment Panel III: Third Report of the National Cholesterol Education Program Expert Panel on Detection, Evaluation, and Treatment of High Blood Cholesterol in Adults (Adult Treatment Panel III). Publication 01-3670. Bethesda, MD: National Institutes of Health; 2002:1-50. NIH Publication No. 02-5215.

6. Adult Treatment Panel III: Third Report of the National Cholesterol Education Program (NCEP) Expert Panel on Detection, Evaluation, and Treatment of High Blood Cholesterol in Adults (Adult Treatment Panel III) final report. Circulation 2002, 106:3143-3421.

7. The International Diabetes Federation: The IDF consensus worldwide definition of metabolic syndrome [article online]; 2005. In: http://www.idf.org/ webdata/docs/MetS_def_update2006.pdf.

8. Grundy SM, Brewer HB Jr, Cleeman Jl, Smith SC Jr, Lenfant C: Definition of metabolic syndrome: Report of the National Heart, Lung, and Blood Institute/American Heart Association conference on scientific issues related to definition. Circulation 2004, 109:433-438.

9. Grundy SM, Cleeman Jl, Daniels SR, Donato KA, Eckel RH, Franklin BA, Gordon DJ, Krauss RM, Savage PJ, Smith SC Jr, Spertus JA, Costa F, American Heart Association; National Heart, Lung, and Blood Institute: Diagnosis and management of the metabolic syndrome: an American Heart Association/National Heart, Lung, and Blood Institute Scientific Statement. Circulation 2005, 112:2735-2752.

10. Alberti KG, Eckel RH, Grundy SM, Zimmet PZ, Cleeman Jl, Donato KA, Fruchart JC, James WP, Loria CM, Smith SC Jr, International Diabetes Federation TaskForce on Epidemiology and Prevention; Hational Heart, Lung, and Blood Institute; American Heart Association; World Heart Federation; InternationalAtherosclerosis Society; International Association for the Study of Obesity: Harmonizing the metabolic syndrome: a joint interim statement of the International Diabetes Federation Task Force on Epidemiology and Prevention; National Heart, Lung, and Blood Institute; American Heart Association; World Heart Federation; International Atherosclerosis Society; and International Association for the Study of Obesity. Circulation 2009, 120:1640-1645.

11. Ford ES, Giles WH, Dietz WH: Prevalence of the metabolic syndrome among US adults: findings from the third National Health and Nutrition Examination Survey. JAMA 2002, 287:356-359.

12. Ford ES, Giles WH, Mokdad AH: Increasing prevalence of the metabolic syndrome among u.s. Adults. Diabetes Care 2004, 27:2444-2449.

13. Samaras K, Wand H, Law M, Emery S, Cooper D, Carr A: Prevalence of metabolic syndrome in HIV-infected patients receiving highly active antiretroviral therapy using International Diabetes Foundation and Adult Treatment Panel III criteria: associations with insulin resistance, disturbed body fat compartmentalization, elevated C-reactive protein, and [corrected] hypoadiponectinemia. Diabetes Care 2007, 30:113-119.

14. Bonfanti P, Giannattasio C, Ricci E, Facchetti R, Rosella E, Franzetti M, Cordier L, Pusterla L, Bombelli M, Sega R, Quirino T, Mancia G: HIV and metabolic syndrome: a comparison with the general population. J Acquir Immune Defic Syndr 2007, 45:426-431.

15. Grinspoon SK: Metabolic syndrome and cardiovascular disease in patients with human immunodeficiency virus. Am J Med 2005, 118(Suppl 2):23S-28S.

16. Nolan D: Metabolic complications associated with HIV protease inhibitor therapy. Drugs 2003, 63:2555-2574.

17. Chobanian AV, Bakris GL, Black HR, Cushman WC, Green LA, Izzo JL Jr, Jones DW, Materson BJ, Oparil S, Wright JT Jr, Roccella EJ, National Heart, Lung, and Blood Institute Joint National Committee on Prevention, Detection, Evaluation, and Treatment of High Blood Pressure; National High Blood PressureEducation Program Coordinating Committee: The Seventh Report of the Joint National Committee on Prevention, Detection, Evaluation, and Treatment of High Blood Pressure: the JNC 7 report. JAMA 2003, 289:2560-2572.

18. SBC: I Diretriz Brasileira de Diagnóstico e Tratamento da Síndrome Metabólica. Ara Bras Cardiol 2005, 84(1):S1-S28.

19. O'Brien $E$, Mee F, Atkins $N$, Thomas M: Evaluation of three devices for selfmeasurement of blood pressure according to the revised British Hypertension Society Protocol: the Omron HEM-705CP, Philips HP5332, and Nissei DS-175. Blood Press Monit 1996, 1:55-61.

20. World Health Organization: Physical status: the use and interpretation of anthropometry. Report of the WHO Expert Committee. World Health Organ Tech Rep Ser 1995, 854:1-452.

21. Friedewald WT, Levy Rl, Fredrickson DS: Estimation of the concentration of low-density lipoprotein cholesterol in plasma, without use of the preparative ultracentrifuge. Clin Chem 1972, 18:499-502.

22. Bucolo G, David H: Quantitative determination of serum triglycerides by the use of enzymes. Clin Chem 1973, 19:476-482.

23. Trinder $P$ : Determination of blood glucose using an oxidase-peroxidase system with a non-carcinogenic chromogen. J Clin Pathol 1969, 22:158-161.

24. PN/DST/AIDS: Ministério da Saúde do Brasil - Programa Nacional de Doenças Sexualmente Transmissiveis / AIDS - Rede Nacional de Labortórios de CD4 +/CD8+ e de Carga Viral; 2009. In: http://www.aids.gov.br/data/.

25. Engel LS, Chow WH, Vaughan TL, Gammon MD, Risch HA, Stanford JL, Schoenberg JB, Mayne ST, Dubrow R, Rotterdam H, West AB, Blaser M, Blot WJ, Gail MH, Fraumeni JF Jr: Population attributable risks of esophageal and gastric cancers. J Natl Cancer Inst 2003, 95:1404-1413.

26. Yusuf S, Hawken S, Ounpuu S, Dans T, Avezum A, Lanas F, McQueen M, Budaj A, Pais P, Varigos J, Lisheng L, INTERHEART Study Investigators: Effect of potentially modifiable risk factors associated with myocardial infarction in 52 countries (the INTERHEART study): case-control study. Lancet 2004, 364:937-952.

27. Levine B: What does the population attributable fraction mean? Prev Chronic Dis 2007, 4:A14.

28. Grunfeld C, Kotler DP, Hamadeh R, Tierney A, Wang J, Pierson RN: Hypertriglyceridemia in the acquired immunodeficiency syndrome. Am J Med 1989, 86:27-31.

29. Meenan J, Mooney E, Mosquita N, Johnson AH, Collins P, Feely J, Mulcahy FM: The impact of HIV disease progression on serum lipoproteins. AIDS 1992, 6:1551-1552.

30. Jacobson DL, Tang AM, Spiegelman D, Thomas AM, Skinner S, Gorbach SL, Wanke C: Incidence of metabolic syndrome in a cohort of HIV-infected adults and prevalence relative to the US population (National Health and Nutrition Examination Survey). J Acquir Immune Defic Syndr 2006, 43:458-466. 
31. Squillace N, Zona S, Stentarelli C, Orlando G, Beghetto B, Nardini G, Esposito R, Guaraldi G: Detectable HIV Viral Load Is Associated With Metabolic Syndrome. J Acquir Immune Defic Syndr 2009, 52:459-464.

32. Hansen BR, Petersen J, Haugaard SB, Madsbad S, Obel N, Suzuki Y, Andersen $\mathrm{O}$ : The prevalence of metabolic syndrome in Danish patients with HIV infection: the effect of antiretroviral therapy. HIV Med 2009, 10:378-387.

33. Bonfanti P, Ricci E, de Socio G, Zeme D, Carradori S, Penco G, Parruti G, Grosso C, Madeddu G, Vichi F, Bini T, Martinelli C, Melzi S, Quirino T, CISAI StudyGroup: Metabolic syndrome: a real threat for HIV-positive patients?: Results from the SIMONE study. J Acquir Immune Defic Syndr 2006, 42:128-131.

34. Gus M, Cichelero FT, Moreira CM, Escobar GF, Moreira LB, Wiehe M, Fuchs SC, Fuchs FD: Waist circumference cut-off values to predict the incidence of hypertension: an estimation from a Brazilian population-based cohort. Nutr Metab Cardiovasc Dis 2009, 19:15-19.

35. Donato GB, Fuchs SC, Oppermann K, Bastos C, Spritzer PM: Association between menopause status and central adiposity measured at different cutoffs of waist circumference and waist-to-hip ratio. Menopause 2006, 13:280-285.

36. Athyros VG, Ganotakis ES, Tziomalos K, Papageorgiou AA, Anagnostis P, Griva T, Kargiotis K, Mitsiou EK, Karagiannis A, Mikhailidis DP: Comparison of four definitions of the metabolic syndrome in a Greek (Mediterranean) population. Curr Med Res Opin 2010, 26:713-719.

37. Panagiotakos DB, Pitsavos C, Das UN, Skoumas Y, Stefanadis C: The implications of anthropometric, inflammatory and glycaemic control indices in the epidemiology of the metabolic syndrome given by different definitions: a classification analysis. Diabetes Obes Metab 2007, 9:660-668.

38. Ascaso JF, Romero P, Real JT, Lorente Rl, Martinez-Valls J, Carmena R: Abdominal obesity, insulin resistance, and metabolic syndrome in a southern European population. Eur J Intern Med 2003, 14:101-106.

39. Bernal E, Masia M, Padilla S, Martin-Hidalgo A, Gutierrez F: Prevalence and characteristics of metabolic syndrome among HIV-infected patients from a Mediterranean cohort]. Med Clin (Barc) 2007, 128:172-175. quiz 171 p following 200

40. Jerico C, Knobel H, Montero M, Ordonez-Llanos J, Guelar A, Gimeno JL, Saballs P, López-Colomés JL, Pedro-Botet J: Metabolic syndrome among HIV-infected patients: prevalence, characteristics, and related factors. Diabetes Care 2005, 28:132-137.

doi:10.1186/1742-6405-9-29

Cite this article as: Alencastro et al: Metabolic syndrome and population attributable risk among HIV/AIDS patients: comparison between NCEPATPIII, IDF and AHA/NHLBI definitions. AIDS Research and Therapy 2012 9:29.

\section{Submit your next manuscript to BioMed Central and take full advantage of:}

- Convenient online submission

- Thorough peer review

- No space constraints or color figure charges

- Immediate publication on acceptance

- Inclusion in PubMed, CAS, Scopus and Google Scholar

- Research which is freely available for redistribution 